\title{
EFFECT OF POLYMERS ON THE PHYSICOCHEMICAL AND DRUG RELEASE PROPERTIES OF TRANSDERMAL PATCHES OF ATENOLOL
}

\section{MANISH KUMAR ${ }^{a}$, VISHAL TRIVEDI ${ }^{\mathrm{b}}$, AJAY KUMAR SHUKLA ${ }^{\mathrm{a}}$, SURESH KUMAR DEV ${ }^{\mathrm{a}}$}

aDepartment of Pharmaceutical Sciences, Mohanlal Sukhadia University, Udaipur, Rajasthan, India, bDepartment of Pharmaceutical Sciences, Madhav University, Pindwara, Rajasthan, India Email: manishsip@gmail.com

Received: 22 Jan 2018, Revised and Accepted: 24 May 2018

\section{ABSTRACT}

Objective: The objective of this research work was to develop a transdermal drug delivery system containing atenolol with different ratios of hydrophilic and hydrophobic polymeric combinations, using solvent evaporation technique and to examine the effect of hydrophilicity and hydrophobicity of polymers on the physicochemical and drug release properties of transdermal patches.

Methods: Solvent casting method has been used to formulate transdermal patches. Hydroxypropyl methylcellulose (HPMC), Polyvinylpyrrolidone (PVP), Ethylcellulose (EC) in different combination ratios were used as the polymer. Propylene glycol was used as a plasticizer. Permeation enhancers such as span 80 were used to enhance permeation through the skin. In vitro diffusion study was carried out by franz diffusion cell using egg membrane as a semi-permeable membrane for diffusion.

Results: Result showed that the thickness of the all batch of patches varied from 0.32 to 0.39 mm with uniformity of thickness in each formulation. Formulations F1 to F3 had high moisture content varied from $2.07 \pm 0.09$ to $2.56 \pm 0.15$ and high moisture uptake value varied from $3.21 \pm 0.35$ to $4.09 \pm 0.38$, due to a higher concentration of hydrophilic polymers. Drug content of all batches was ranged between $85.92 \pm 1.32$ to $95.71 \pm 1.42$. Folding endurance values off all batches were more than 75. Formulation batches F1 to F3 showed higher cumulative drug release varied from $61.34 \%$ to $68.11 \%$ as compared to formulation batches F4 to F6.

Conclusion: Higher proportion of hydrophilic polymer in the formulation of transdermal patches, gives higher percentage drug release from prepared patches. The finding of the study indicates that hydrophilicity and hydrophobicity of polymer effects the physicochemical and drug release properties of transdermal patches and an optimum proportion of hydrophilic and hydrophobic polymer is required for the preparation of effective transdermal patches.

Keywords: Transdermal drug delivery systems (TDDS), Transdermal patches, Atenolol, HPMC, Hydrophilic polymer, Hydrophobic polymer, Drug release

(C) 2018 The Authors. Published by Innovare Academic Sciences Pvt Ltd. This is an open access article under the CC BY license (http://creativecommons.org/licenses/by/4.0/) DOI: http://dx.doi.org/10.22159/ijap.2018v10i4.24916

\section{INTRODUCTION}

Transdermal drug delivery system (TDDS) is a promising approach in novel drug delivery systems [1]. Transdermal system delivers the drugs for the systemic effects at a controlled rate for an extended period [2]. It is an effective approach for systemic delivery of drugs which have low absorption, short half-lives, and high first-pass metabolism [3-4]. Transdermal system provides steady absorption of the drug over a long period of time with the facility of immediate withdrawal of the treatment if necessary [5-6]. It also reduces the dosing frequency and patient variability [7-8]. Transdermal drug delivery system consists of a patch that contains drug substance and pressed on to skin. Transdermal patches are non-invasive, convenient, painless mode of drug administration and can avoid gastrointestinal toxicity [9]. In this study, we attempt to formulate the transdermal patches of atenolol. Atenolol is a $\beta_{1}$-receptor selective antagonist, used in treating hypertension, angina, heart failure, and myocardial infarction; chemically, it is 4-(2-hydroxyl-3-isopropylaminopropoxy) phenylacetamide. Atenolol has slight water solubility, half-lives of 6-7 h. and incomplete absorption from the gastrointestinal tract (GIT) [10].

Selection of polymers are important for the formulation of TDDS. Polymers have the film forming capacity. When a solution of the polymer in a suitable solvent, spreads on a flat surface and allow to evaporate then a thin film of polymer is left behind. Similarly, if the drug is incorporated in polymer-solvent then drug molecules are dispersed in the polymer film and forms the drug-loaded films. Hence drug release entirely depends on polymer [11].

Nature and type of polymers effects the physicochemical and drug release properties of transdermal patches. Investigation of the effects of hydrophilic and hydrophobic nature of the polymer, on physicochemical and drug release properties of transdermal patches, is crucial for the optimizing drug release characteristics of transdermal patches. The aim of this study was to develop a transdermal therapeutic system containing atenolol with different ratios of hydrophilic and hydrophobic polymeric combinations, using solvent evaporation technique and to examine the effect of hydrophilicity and hydrophobicity of polymers on the physicochemical and drug release properties of transdermal patches as well as to optimizing the proportion of hydrophilic and hydrophobic polymer for providing better control on drug release characteristics in transdermal patches.

\section{MATERIALS AND METHODS}

\section{Materials}

Atenolol, hydroxypropyl methylcellulose (HPMC), polyvinylpyrrolidone (PVP), ethyl cellulose (EC) was gift sample from molecular lab Ahmadabad. Propylene glycol and span 80 were of laboratory grade. Franz diffusion cell (Ponmani and Co, Coimbatore), magnetic stirrer (Remi equipment Ltd., Vasai), pH meter (Hanna Instruments, Italy), ultra-violet/visible (UV/VIS) spectrophotometer (Shimadzu, Indore), fourier-transform infrared (FTIR) spectrometers (Brukar optics. Germany) were also used.

\section{Methods}

\section{Preparation of calibration curve of atenolol}

The calibration curve was prepared with phosphate buffer $\mathrm{pH} 7.4$ by measuring the absorbance at $275 \mathrm{~nm}$. Calibration curve prepared by taking absorbance of five serial dilutions of stoke solution on UV/VIS spectrophotometer and plotting the graph between absorbance versus concentration of the drug.

\section{Compatibility study}

Compatibility of the drug with polymer mixture was tested on Fourier transform infrared spectrometer (FTIR). 


\section{Preparation of transdermal patches of atenolol}

Matrix patches were prepared by a solvent casting method. Matrix patches of varying polymer and composition were prepared in water/methanol (1:1) mixture according to table 1 . Propylene glycol
$20 \% \mathrm{w} / \mathrm{w}$ of dry weight of the polymer was used as a plasticizer. Span 80 was used as a permeation enhancer. Drug was dissolved and mixed in the polymer solution and stirred until a clear solution obtained. Then the solution was poured into a transdermal mold and dried in a desiccator at room temperature.

Table 1: Fabrication of transdermal patches of atenolol

\begin{tabular}{|c|c|c|c|c|c|c|}
\hline Ingredient & F1 & F2 & F3 & F4 & F5 & F6 \\
\hline Drug (\%w/w) & 30 & 30 & 30 & 30 & 30 & 30 \\
\hline HPMC $(\% w / w)$ & 80 & 70 & 60 & 80 & 70 & 60 \\
\hline PVP (\%w/w) & 20 & 30 & 40 & - & - & - \\
\hline $\mathrm{EC}(\% \mathrm{w} / \mathrm{w})$ & - & - & - & 20 & 30 & 40 \\
\hline Span $80(\% \mathrm{w} / \mathrm{w})$ & $10 \%$ & veigl & mer & & & \\
\hline Propylene glycol (\%w/w) & $20 \%$ & veigl & mer & & & \\
\hline
\end{tabular}

HPMC-Hydroxy propyl methyl cellulose, PVP-Polyvinylpyrrolidone, EC-Ethyl cellulose

\section{Evaluation of transdermal patches}

\section{The thickness of the patch}

Thickness of the films was measured at different places of patches by using varnier caliper and an average of five readings was taken.

\section{Percentage of moisture content}

High concentration of hydrophilic polymer in formulation increases the moisture content of patches. So, for testing of moisture content, the prepared films were weighed separately and put in a desiccator containing calcium chloride at room temperature for $24 \mathrm{~h}$. At specified intervals, the films were weighed continuously until they showed a constant weight. The percentage (\%) moisture content was calculated using following formula [12].

$$
\text { \% Moisture content }=\frac{\text { Initial weight }- \text { Final weight }}{\text { Final weight }} \times 100
$$

\section{Percentage of moisture uptake}

Percentage of moisture uptake study was also done to check the effect of hydrophilic polymer on moisture uptake capacity of patches. For determining percentage of moisture uptake, the prepared films were weighed separately and put in a desiccator with silica gel for $24 \mathrm{~h}$ and then were taken outweighed and exposed to $84 \%$ relative humidity using saturated solution of potassium chloride in a desiccator until a constant weight was achieved. Percentage moisture uptake was calculated as given below [12].

$$
\text { \% Moisture uptake }=\frac{\text { Final weight }- \text { Initial weight }}{\text { Initial weight }} \times 100
$$

\section{Test for drug content}

An accurately weighed portion of film (about $100 \mathrm{mg}$ ) was dissolved in $100 \mathrm{ml}$ volumetric flask containing phosphate buffer $(\mathrm{pH} 7.4)$ and then the flask was sonicated for $8 \mathrm{~h}$. After sonication, the solution was then filtered using a $0.45 \mu \mathrm{m}$ filter and the drug content was analyzed at $275 \mathrm{~nm}$ by UV spectrophotometer [13].

\section{Folding endurance}

Folding endurance value expresses the folding capacity of the films subjected to frequent extreme conditions of folding. Folding endurance was determined by repeatedly folding the film at the same place until it breaks. The number of times the films could be folded at the same place without breaking was folding endurance value [14].

\section{In vitro diffusion studies}

For in vitro diffusion study, franz diffusion cell was used. The franz diffusion cell contains donor and receptor compartment. Egg membrane was used as semi-permeable membrane for diffusion and it was mounted between donor and receptor compartment. A weighed amount of transdermal patch was placed on one side of the membrane. Phosphate buffer of $\mathrm{pH} 7.4$ was filled in receptor compartment. To maintain the temperature at $37 \pm 0.5^{\circ} \mathrm{C}$, water jacket surrounded the receptor compartment. Fluid in receptor compartment was stirred continuously by magnetic beads. At specific intervals of time, sample was withdrawn from the receptor compartment and the same volume of phosphate buffer $\mathrm{pH} 7.4$ was added to receptor compartment to maintain sink conditions. The samples were analyzed at $275 \mathrm{~nm}$ UVspectrophotometrically [15].

\section{RESULTS AND DISCUSSION}

\section{Calibration curve of atenolol}

The calibration curve was prepared with phosphate buffer $\mathrm{pH} 7.4$. The coefficient of determination $\left(\mathrm{R}^{2}\right)$ value was found to be 0.9879 . Calibration curve data of atenolol are showed in table 2 .

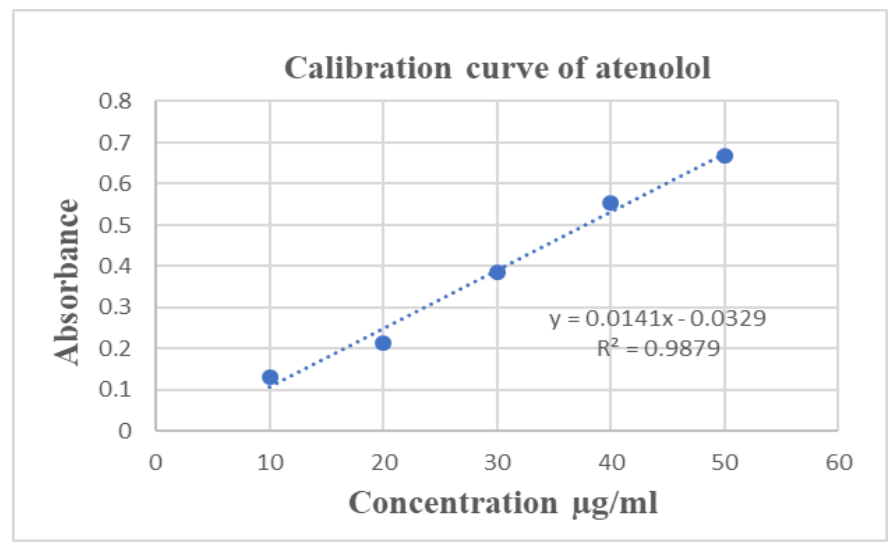

Fig. 1: Standard graph of atenolol in phosphate buffer pH 7.4 
Table 2: Calibration curve data of atenolol

\begin{tabular}{lll}
\hline S. No. & Concentration $(\mu \mathrm{g} / \mathbf{m l})$ & Absorbance \\
\hline 1. & 10 & 0.132 \\
2. & 20 & 0.213 \\
3. & 30 & 0.386 \\
4. & 40 & 0.554 \\
5. & 50 & 0.667 \\
\hline
\end{tabular}

\section{Compatibility study}

The drug was identified and compatibility was confirmed by FTIR spectrum from fig. 2, 3, and 4. From FTIR spectra, it was revealed that there is no interaction between the drug and polymer mixture (HPMC, PVP, and EC)

\section{The thickness of the patch}

The thickness of all batch of the patches varied from $0.32 \pm 0.02$ to $0.39 \pm 0.01$ millimetre $(\mathrm{mm})$. The values obtained for all the formulations are given in the table 3 . The low (standard deviation)
SD values in the patches thickness measurements ensured uniformity of thickness in each formulation.

\section{Percentage moisture content}

Higher moisture content can cause the degradation of the patch Percentage moisture content of transdermal patches was found within criteria. Formulations F1 to F3 had high moisture content due to a higher concentration of hydrophilic polymers. Kaur et al. [16] also founded a similar result with a higher concentration of hydrophilic polymers in patches. Percentage moisture content value of all formulation batches have given in table 4 .

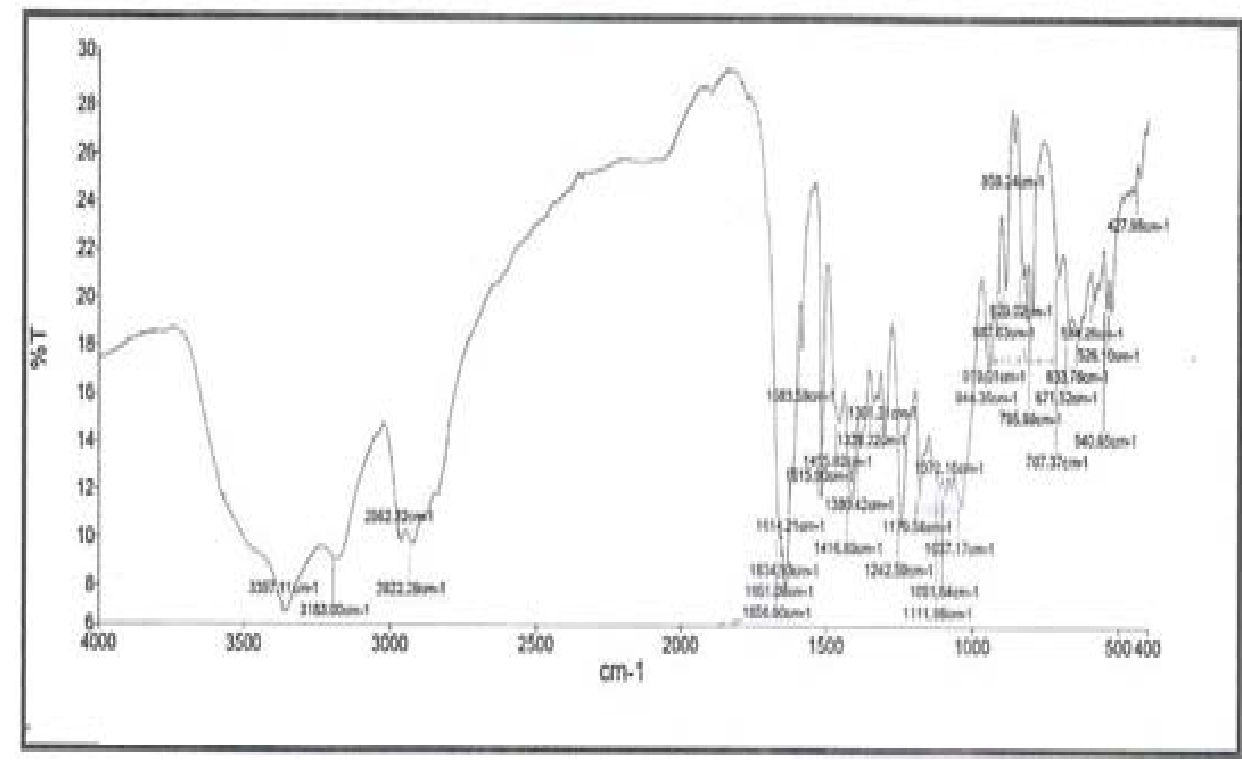

Fig. 2: IR spectrum of atenolol

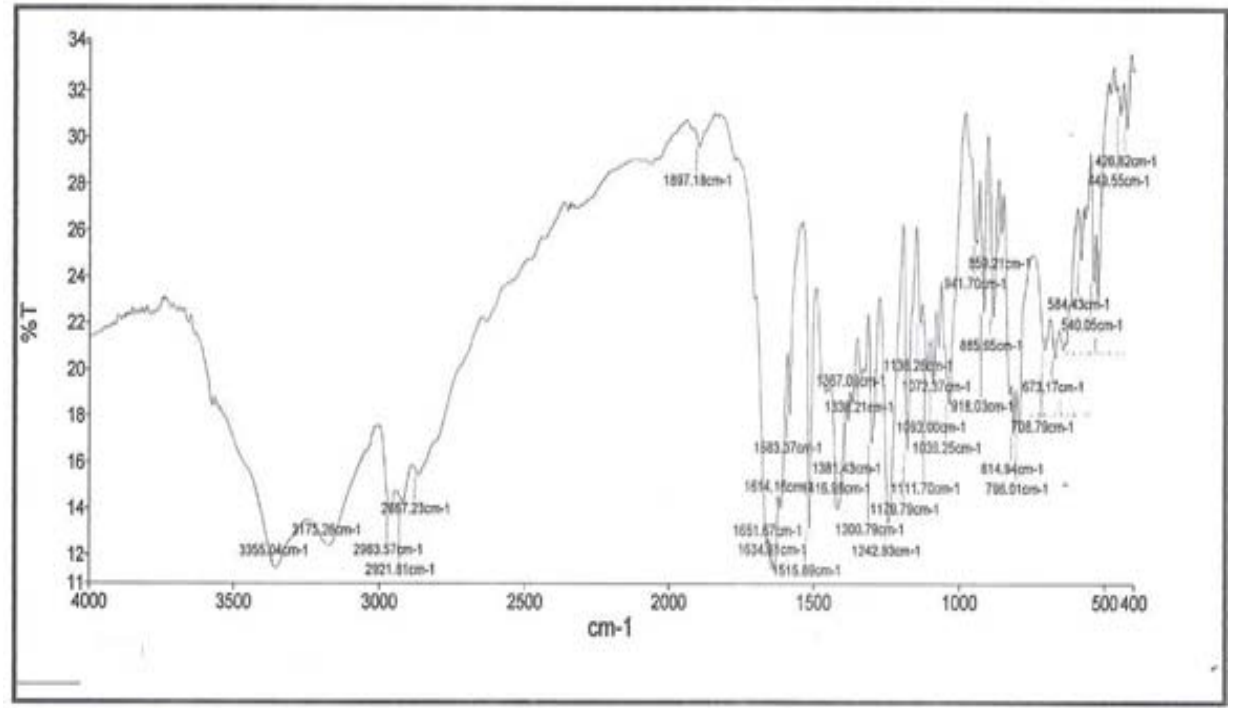

Fig. 3: IR spectrum of atenolol+(HPMC+PVP mixture) 


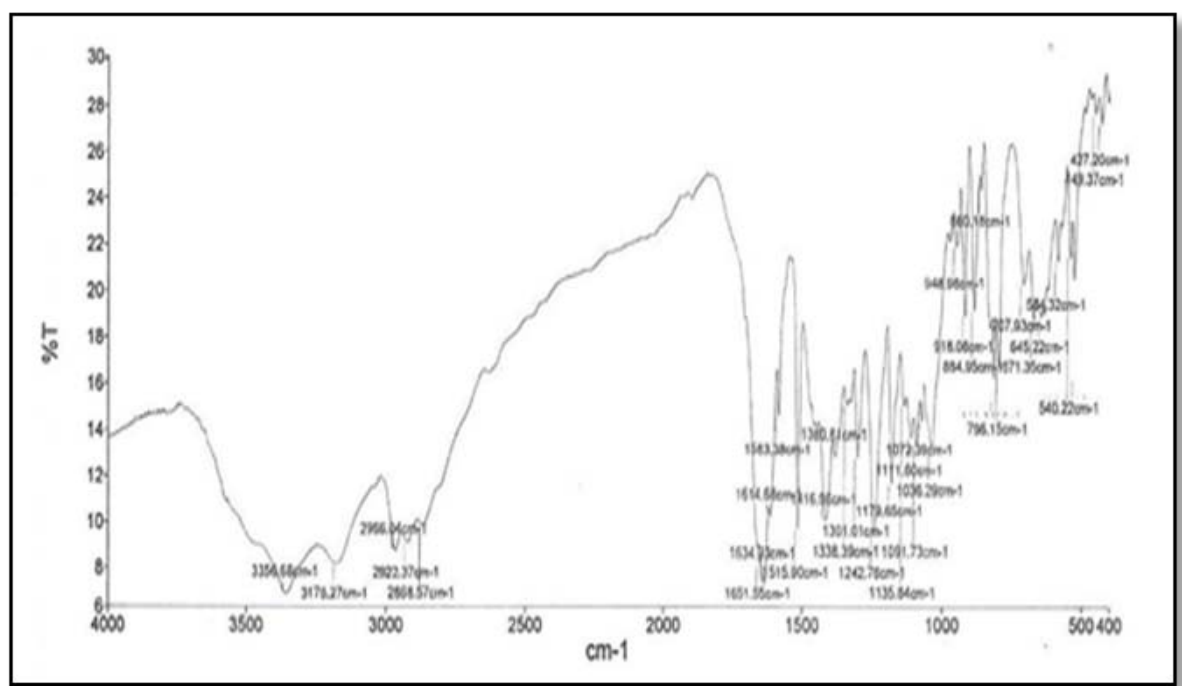

Fig. 4: IR spectrum of atenolol+(HPMC+ECmixture)

Table 3: Thickness of the patches

\begin{tabular}{|c|c|c|c|c|c|c|}
\hline S. No./Code & F1(mm) & F2(mm) & F3(mm) & F4(mm) & F5(mm) & F6(mm) \\
\hline 1 & 0.33 & 0.34 & 0.30 & 0.39 & 0.37 & 0.40 \\
\hline 2 & 0.37 & 0.32 & 0.32 & 0.38 & 0.36 & 0.37 \\
\hline 3 & 0.30 & 0.39 & 0.30 & 0.32 & 0.32 & 0.39 \\
\hline 4 & 0.31 & 0.31 & 0.33 & 0.40 & 0.36 & 0.38 \\
\hline 5 & 0.34 & 0.29 & 0.36 & 0.36 & 0.40 & 0.40 \\
\hline mean \pm SD & $0.33 \pm 0.03$ & $0.33 \pm 0.04$ & $0.32 \pm 0.02$ & $0.37 \pm 0.03$ & $0.36 \pm 0.03$ & $0.39 \pm 0.01$ \\
\hline
\end{tabular}

mean \pm SD, $n=5$, SD-Standard Deviation.

Table 4: Moisture content of patches

\begin{tabular}{lll}
\hline S. No. & Formulation code & \% Moisture content (mean \pm SD) \\
\hline 1. & F1 & $2.10 \pm 0.16$ \\
2. & F2 & $2.07 \pm 0.09$ \\
3. & F3 & $2.56 \pm 0.15$ \\
4. & F4 & $1.58 \pm 0.10$ \\
5. & F5 & $1.37 \pm 0.11$ \\
6. & F6 & $1.13 \pm 0.08$ \\
\hline
\end{tabular}

mean $\pm S D, n=3$, SD-Standard Deviation.

\section{Percentage moisture uptake}

Formulations F1 to F3 had higher moisture uptake as compare to other batches due to higher concentration of hydrophilic polymers. Hydrophilic polymers absorb moisture faster and to a greater extent than the hydrophobic polymers thus formulation batches F1 to F3 gave high moisture uptake value. Sethi et al. [17] in their research also got similar results with a hydrophilic polymer. Percentage moisture uptake value of all formulation batches have given in table 5 .

Table 5: Moisture uptake of patches

\begin{tabular}{lll}
\hline S. No. & Formulation code & \% Moisture uptake (mean \pm SD) \\
\hline 1 & F1 & $3.21 \pm 0.35$ \\
2 & F2 & $3.34 \pm 0.30$ \\
3 & F3 & $4.09 \pm 0.38$ \\
4 & F4 & $2.47 \pm 0.15$ \\
5 & F5 & $2.22 \pm 0.18$ \\
6 & F6 & $2.01 \pm 0.09$ \\
\hline
\end{tabular}

mean $\pm S D, n=3, S D-S t a n d a r d$ Deviation.

\section{Test for drug content}

The percentage of drug content in all formulations batches varied between the ranges $85.92 \pm 1.32$ to $95.71 \pm 1.42 \%$. Batches with a high content of hydrophobic polymers (F4 to F6) showed high drug content value. Low SD value in batches indicated that the drug dispersed uniformly throughout the polymeric film in each batch. Percentage drug content of all formulation batches has given in table 6 . 
Table 6: Test for $\%$ drug content in patches

\begin{tabular}{lll}
\hline S. No. & Formulation code & \% Drug content (mean \pm SD) \\
\hline 1 & F1 & $85.92 \pm 1.32$ \\
2 & F2 & $88.59 \pm 1.14$ \\
3 & F3 & $87.51 \pm 2.17$ \\
4 & F4 & $94.65 \pm 2.42$ \\
5 & F5 & $91.36 \pm 2.02$ \\
6 & F6 & $95.71 \pm 1.42$ \\
\hline
\end{tabular}

mean $\pm S D, n=3$, SD-Standard Deviation.

\section{Folding endurance}

Folding endurance values have given in table 7 . The highest folding endurance value was observed for F5 batch and the lowest was observed for F1 batch. The high folding endurance value indicates that has the high mechanical property of patches [18]. These results indicated that the patches would not break under frequent extreme conditions of folding and ensured flexibility of formulated transdermal patches.

Table 7: Folding endurance values

\begin{tabular}{lll}
\hline S. No. & Formulation code & Folding endurance (mean \pm SD) \\
\hline 1 & F1 & $76 \pm 2.52$ \\
2 & F2 & $87 \pm 4.04$ \\
3 & F3 & $85 \pm 3.51$ \\
4 & F4 & $98 \pm 2.52$ \\
5 & F5 & $101 \pm 2.53$ \\
6 & F6 & $94 \pm 3.06$ \\
\hline
\end{tabular}

mean $\pm S D, n=3$, SD-Standard Deviation

\section{In vitro diffusion studies}

In vitro diffusion study was carried out by using franz diffusion cell and egg membrane was used as semi-permeable membrane for diffusion. Percentage cumulative drug release was determined for all 6 batches and result is shown in table 8 and fig. 5 . The percentage cumulative drug release was found to be higher for formulation batches F1 to F3 as compared to formulation batches F4 to F6. Formulation batches F1 to F3 gave higher percentage cumulative drug release because they had a higher proportion of hydrophilic polymer as compared to formulation batches F4 to F6. The same result with hydrophilic polymers is also obtained by Hardainiyan et al. [19] and Sadhasivam et al. [20]. High polymer content in patches provides faster polymer matrix dissolution in aqueous media thus give higher drug release.

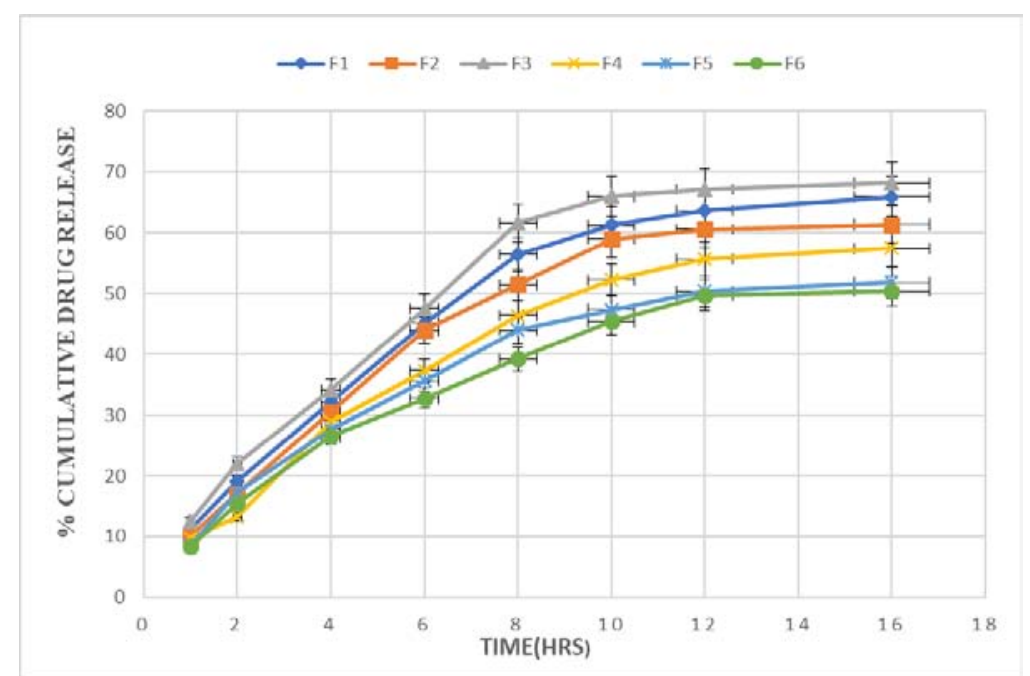

Fig. 5: Percentage cumulative drug release from all formulation batches in $16 \mathrm{~h}$, All the values were calculated as mean \pm standard deviation; $\mathbf{n}=3$

\section{CONCLUSION}

The transdermal patches were prepared by a solvent casting method using a combination of hydrophilic and hydrophobic polymer in different ratio. HPMC, PVP, and EC were used as polymer mixtures. Propylene glycol and span 80 were used as a plasticizer and permeation enhancer, respectively. Total 6 batches (F1to F6) have been prepared by using a combination of HPMC, PVP, and EC in different ratios. The thickness of the patches varied from $0.33 \pm 0.03$ to $0.39 \pm 0.01 \mathrm{~mm}$. Formulation batches F1, F2, and F3 have higher moisture content and uptake values as compared to other batches (F4, F5, F6) due to the presence of higher concentration of hydrophilic polymer (HPMC and PVP).

Folding endurance values of all batches varied from $76 \pm 2.52$ to $101 \pm 2.53$ and drug content were ranged from about $85 \%$ to $96 \%$. In vitro diffusion studies showed that ratio of hydrophilic and hydrophobic polymer in formulation effects the drug release 
characteristics of patches. Formulation batches F1, F2, and F3 have higher cumulative drug release as compared to formulation batches F4, F5 and F6. A higher proportion of hydrophilic polymer (HPMC and PVP) in formulation batches F1, F2 and F3, gives higher \% drug release from patches. Thus, in the formulation of effective and optimum transdermal patches, the proportion of hydrophilic and hydrophobic polymer have a very important role.

\section{ACKNOWLEDGEMENT}

Authors are thankful to the Madhav University, Pindwara, Rajasthan for their technical support.

Financial support and sponsorship: Nil.

\section{AUTHORS CONTRIBUTIONS}

All the authors have contributed equally

\section{CONFLICTS OF INTERESTS}

Declared none

\section{REFERENCES}

1. Ahad A, Al-Mohizea AM, Al-Jenoobi FI, Aqil M. Transdermal delivery of angiotensin II receptor blockers (ARBs), angiotensinconverting enzyme inhibitors (ACEIs) and others for management of hypertension. Drug Delivery 2016;23:579-90.

2. Cherukuri S, Batchu UR, Mandava K, Cherukuri V, Ganapuram KR. Formulation and evaluation of transdermal drug delivery of topiramate. Int J Pharm Invest 2017;7:10-7.

3. Pastore MN, Kalia YN, Horstmann M, Roberts MS. Transdermal patches: history, development, and pharmacology. $\mathrm{Br} J$ Pharmacol 2015;172:2179-209.

4. Balaji P, Thirumal M, Gowri R, Divya V, Ramaswamy V. Design, and evaluation of matrix type of transdermal patches of methotrexate. Int J Pharm Chem Biol Sci 2012;2:464-71.

5. Subedi RK, Oh SY, Chun MK, Choi HK. Recent advances in transdermal drug delivery. Arch Pharmacal Res 2010;33:339-51.

6. Keith AD. Polymer matrix consideration for transdermal devices. Drug Dev Ind Pharm 1983;9:605-21.

7. Ahad A, Aqil M, Kohli K, Chaudhary H, Sultana Y, Mujeeb M, et al. Chemical penetration enhancers: a patent review. Expert Opin Ther Pat 2009;19:969-88.
8. Aqil M, Ahad A, Sultana Y, Ali A. Status of terpenes as skin penetration enhancers. Drug Discovery Today 2007;12:1061-7.

9. Agrawal SS, Munjal P. Permeation studies of atenolol and metoprolol tartrate from three different polymer matrices for transdermal delivery. Indian J Pharm Sci 2007;69:535-9.

10. Adhikari SNR, Nayak BS, Nayak AK, Mohanty B. Formulation and evaluation of buccal patches for delivery of atenolol. AAPS PharmSciTech 2010;11:1038-44.

11. Kaza R, Pitchaimani R. Formulation of transdermal drug delivery system: matrix type, and selection of polymer-their evaluation. Curr Drug Discovery Technol 2006;3:279-85.

12. Bagyalakshmi J, Vamsikrishna RP, Manavalan R, Ravi TK, Manna PK. Formulation development and in vitro and in vivo evaluation of membrane-moderated transdermal systems of ampicillin sodium in ethanol: $\mathrm{pH} 4.7$ buffer solvent system. AAPS PharmSciTech 2007;8:E50-E55.

13. Costa P, Ferreira DC, Morgado R, Sousa Lobo JM. Design and evaluation of a lorazepam transdermal delivery system. Drug Dev Ind Pharm 1997;23:939-44.

14. Ubaidulla U, Reddy MVS, Ruckmani K, Ahmad FJ, Khar RK Transdermal therapeutic system of carvedilol: Effect of the hydrophilic and hydrophobic matrix on in vitro and in vivo characteristics. AAPS PharmSciTech 2007;8:E13-E20.

15. Murthy SN, Hiremath SRR. Physical and chemical permeation enhancers in transdermal delivery of terbutaline sulphate. AAPS PharmSciTech 2001;2:1-5.

16. Kaur K, Kaur P, Jalhan S, Jain UK. Formulation and in vitro evaluation of transdermal matrix patches of doxofylline. Asian J Pharm Clin Res 2016;9:140-5.

17. Sethi B, Mazumder R. Comparative evaluation of selected polymers and plasticizer on transdermal drug delivery system. Int J Appl Pharm 2018;10:67-73.

18. Das PS, Saha P. Design and characterization of transdermal patches of phenformin hydrochloride. Int J Curr Pharm Res 2017;9:90-3.

19. Hardainiyan S, Kumar K, Nandy BC, Saxena R. Design, formulation, and in vitro drug release from transdermal patches containing imipramine hydrochloride as model drug. Int J Pharm Pharm Sci 2017;9:220-5.

20. Sadhasivam L, Dey N, Francis AP, Devasena T. Transdermal patches of chitosan nanoparticles for insulin delivery. Int J Pharm Pharm Sci 2015;7:84-8. 